\title{
Normal Saline Addition to RFA Increases Energy and Heat Output Leading to Complete HCC Ablation and Higher Cure Rate
}

\author{
Samar K Darweesh ${ }^{1 *}$, Amal A Gad ${ }^{2}$, Doaa F Gad ${ }^{3}$, Mai Ismail Mehrez ${ }^{4}$ and Bahaa Abbas ${ }^{5}$ \\ ${ }^{1}$ Hepatogastroenterology and Endemic Medicine Department, Cairo University, Egypt \\ ${ }^{2}$ Internal Medicine Department, Suez canal University, Egypt \\ ${ }^{3}$ Internal Medicine Department, Mansoura University, Egypt \\ ${ }^{4}$ Fellow of Hepatology, National Hepatology and Tropical Medicine Research institute (NHTMRI), Egypt \\ ${ }^{5}$ Doctor of Hepatology, Airforce specialized Hospital, Egypt
}

Submission: February 10, 2017; Published: March 27, 2017

"Corresponding author: Samar Kamal Darweesh, Associate Professor of Hepato-gastroenterology and Endemic Medicine Department, Faculty of Medicine, Cairo University, Cairo, 63, Abo Dawood El-Thahery St., Nasr city, Cairo, Egypt, Tel: 002- 01000702766; Email: samarkad@hotmail.com

\begin{abstract}
Introduction: One of the potential approaches to increase the effectiveness of radiofrequency ablation (RFA) is to modify the biologic environment of treated tissues. So, several researchers have studied increasing RFA heating by the combined intra-tumoral injection of diverse concentrations and volumes of saline.
\end{abstract}

Aim: Study the effect of normal saline (NS) on cool-tip radiofrequency machine parameters, success rate and frequency of complications when used for ablation of HCV-related hepatocellular carcinoma (HCC).

Patients and methods: This study included 80 patients with HCC (proven by histopathology and/or typical feature on triphasic CT abdomen and significantly elevated alpha-fetoprotein). They were randomly allocated to either cool-tip RFA preceded by intra- tumor normal saline injection, group $1(\mathrm{RFA}+\mathrm{S})$ that included 40 patients, or treated with cool-tip RFA only, group 2 (RFA) that included 40 patients

Results: The RF machine parameters in our study showed that the impedance; (minimum, $\mathrm{P}=0.024$, maximum, $\mathrm{P}=0.027$ and mean, $\mathrm{P}=0.017$ ) and the tip temperature (minimum, $\mathrm{P}=0.19$ maximum, $\mathrm{P}=0.069$ and mean, $\mathrm{P}=0.086$ ) were significantly lower in $\mathrm{RFA}+\mathrm{S}$ group than $\mathrm{RFA}$ group. The current (heat deposition) was significantly higher in $\mathrm{RFA}+\mathrm{S}$ group than RFA group $(\mathrm{P}=0.018)$. The procedure was successful in all the $\mathrm{RFA+S}$ group $40(100 \%)$ compared to $22(55 \%)$ of the RFA alone group ( $\mathrm{P}<0.01)$. Those who failed RFA alone, $18(45 \%)$ were shifted to percutaneous ethanol injection (PEI). The procedure related complications were comparable in both groups with no reported major side effect or death.

Conclusion: Normal saline decreases impedance and increases energy deposition in RFA leading to marked increase in ablation volume and success rate, so, RFA preceded by intra-tumor normal saline injection is more effective than RFA alone. It should be widely used in ablation of HCC as it is safe, highly effective, one session procedure, non-costly and easy to perform.

Keywords: Radiofrequency ablation; Saline; Hepatocellular carcinoma; Energy; Impedance

\section{Introduction}

HCC is probably the most common solid human malignancy in the world. In Egypt, considering the high prevalence of HCV $[1,2]$, it is estimated that the problem of HCC will increase until it reaches its peak in the year 2018 [3,4]. Prior efforts at increasing local tumor ablation by RF have been based on maximizing tissue coagulation by increasing the amount of thermal energy deposited during ablation. Other researchers studied changing the biologic environment of tissues by combining RFA with other ablation therapies, such as intra-tumoral chemotherapy, transcatheter arterial chemoembolization or TACE, intratumoral ethanol or intra-tumoral normal $0.9 \%$ or hypertonic saline solution injection [5-9]. So, the aim of this work was to compare RFA machine parameters; tip temperature, impedance, repeated pulsing and ablation size in cool-tip RFA procedure alone and in combined cool-tip RFA with intra-tumor preprocedural normal saline $(0.9 \%)$ injection in patients with 
hepatocellular carcinoma, with assessment of both techniques" impact on HCC cure rate, HCC recurrence and procedure related complications.

\section{Patients and Methods}

\section{Study patients}

This prospective study was conducted from May 2008 to May 2010 on 80 patients presented to the Hepato-gastroenterology and Endemic Medicine Department, Faculty of Medicine, Cairo University with hepatocellular carcinoma (diagnosed either by Tru- cut liver biopsy or by the presence of both elevated alpha-fetoprotein (AFP) and typically enhancing focal lesions on tri- phasic CT assessment). They were randomly divided (computer based) into two groups, each of 40 patients; group 1 $(\mathrm{RFA}+\mathrm{S})$ who were assigned to cool-tip RFA proceeded by intratumor- saline injection in the same session, and group 2 (RFA) who were assigned to ordinary cool-tip RFA only. This study was approved by the Hepato-gastroenterology and Endemic Medicine Department committee (institution review board) and the institution ethics committee. This study was performed in accordance with the ethics guidelines of the 1975 Declaration of Helsinki. Informed consent was obtained from each participant after explanation of procedures. Patient's eligibility, we excluded patients with: Lesions larger than $5 \mathrm{~cm}$, more than three in number, Child Pugh score C, PV thrombosis, lesions near PV, IVC, GB or sub capsular, metastatic HCC or severe uncontrollable bleeding diathesis (INR more than 1.4 and platelets count less than 50,000).

\section{Study protocol}

Prior to the procedure, all patients were subjected to the following investigations: liver profile (s bilirubin, AST, ALT, ALP, albumin and INR), CBC, AFP, conventional abdominal ultrasound (using a Toshiba SSA. 340 with a $3.5 \mathrm{MHz}$ curved sector transducer), tri-phasic CT of the abdomen [contiguous $5 \mathrm{~mm}$ thick axial CT scans were obtained with a High-Speed Siemens (Erlangen-Germany) machine. Tru-cut biopsy from focal hepatic lesion was performed, if the results of tri-phasic CT and AFP were inconclusive, with a Tru-cut needle 18 gauge and the biopsy was preserved in $10 \%$ formalin till examination. Post RFA procedure assessment.

All laboratory investigations performed pre-procedure were repeated one week post procedure together with US guided biopsy obtained from the treated focal lesions (it was performed in 38 cases of the RFA $+\mathrm{S}$ and 36 cases of the RFA group). AFP and tri- phasic CT was also repeated one week and one month post- procedure. Treatment complete success was considered when; either tri- phasic CT scan shows no arterial phase contrast enhancement inside the lesion post treatment or if histo- pathological assessment shows no viable malignant cells. The response was considered partial when CT scan shows areas of enhancement within the boundaries of the original lesion in the arterial phase or when the pathology shows viable malignant cells.
Patients in the two groups were followed for up to 24 month, for the possibility of RFA related complications, development of liver decompensation, haematemesis, HCC recurrence, and death. The patients with ablated lesions were followed up by AFP and US every 3 months and tri-phasic CT every 6 months. Technique of radiofrequency ablation RFA alone RFA was performed on outpatient bases with the patient under conscious sedation induced by the administration of diazepam 10-20mg (Neuril, Nile) or propofol (Diprivan, Astrazeneca).

RF ablation was performed under real-time US guidance using a $3.5 \mathrm{MHz}$ probe by free hand technique. Two types of $20 \mathrm{~cm}$ long, 18gauge internally-cooled RF electrodes (Radionics, Burlington, MA) were used, depending on the size and location of the tumor. Grounding was achieved by attaching two dispersive pads, each with a greater than $400 \mathrm{~cm} 2$ surface areas, to the patient's thighs. The RFA needle was introduced under US guidance along the planned track till the center of the lesion. The machine (and the chilled saline pump cooling the tip) was started for a session lasting 13 minutes. The pull-back technique: In lesions larger than $4 \mathrm{~cm}$, multiple electrode insertions were required, hyper- echogenicity produced by the RF energy obscured the deeper portions of the tumor and made repositioning of the RF electrode difficult. Therefore, we started at the deeper portions of the lesion; then, after the RFA cycle ended (13min), the electrode was pulled up for $1 \mathrm{~cm}$ and $\mathrm{RF}$ reapplied (pull back) for another 13 minutes. After the session, the tumor turns out to be completely hyper-echoic by US due to gases evaporation and tissue coagulation. Following RFA therapy, patients were put under observation for 6 hours and vital signs were checked every half an hour then they were discharged.

\section{Machine parameters during session}

The RF electrodes were attached to a $500 \mathrm{KHz}$ RF generator (series CC-1; Radionics) capable of producing $200 \mathrm{~W}$ of power. Impedance, tip temperature and current (energy deposition) were continuously displayed and were recorded during the procedure. A thermocouple embedded within the electrode tip continuously measured local tip and tissue temperature during the procedure. A peristaltic pump (Watson- Marrow, Medford, MA) was used to infuse chilled saline into and within the lumen of the electrodes at a rate sufficient to maintain a tip temperature of $20-25{ }^{\circ} \mathrm{C}$ to prevent charring around the needle which will subsequently prevent heat propagation.

Tissue impedance was monitored by circuitry incorporated within the generator. As impedance increases (the resistance of the coagulated tissue to the spread of the RF waves increases), the RF machine automatically turns off and the current (RF energy) indicator returns to zero; this means that the energy deposition in tissues is stopped (cut off occurred). This lasts for several seconds up to minutes until the impedance decreases; then the machine turns on automatically and energy deposition starts again. This process is repeated many times during the 13 min of the RF application session (we called the repeated cut off "pulsing"). 
The total energy and heat deposition depends on the total duration when the current indicator is on (not zero during high impedance) and the longer the total duration of active current indicator the larger the area of coagulation within and around the lesion. On the contrary, when the current indicator is around zero repeatedly (repeated pulsing) for minutes during the session, this indicates inefficient heat propagation and tissue coagulation.

\section{Combined RFA and saline technique}

The RFA technique used was the same as in ordinary RFA but it was preceded by ultrasound insertion of a spinal needle (18gauge) intra-tumor. The RFA needle was inserted intratumor beside the spinal needle, and saline was injected (2$20 \mathrm{cc}$ according to the size of the lesion until the tumor was saturated); the spinal needle was pulled, then the RFA session was immediately started as usual.

\section{Statistical methods}

Quantitative variables were presented using mean and SD, median, and minimum and maximum values. Qualitative data were presented using frequencies and percentage. Chi-square and Fisher's exact tests were used for detection of association whenever appropriate. Comparison of lab data before and after intervention was done using the Wilcoxon Signed Rank test. Binary logistic regression analysis was used to exclude the effect of significant variables between groups on the significant final outcome difference. Differences were considered significant when $\mathrm{P}$ was $\leq 0.05$ and highly significant when $\mathrm{P}$ was $\leq 0.01$.

\section{Results}

\section{Basic characteristics of patients}

Table 1: Tri- phasic CT findings before procedure in both groups.

\begin{tabular}{|c|c|c|c|c|c|}
\hline Item & \multicolumn{2}{|c|}{$\mathrm{RFA}+\mathrm{S}$} & \multicolumn{2}{|c|}{ RFA } & P Value \\
\hline Number & No/38 & $\%$ & $\%$ & No/34 & \\
\hline 1 & 16 & 42 & 18 & 53 & \multirow{4}{*}{0.39 (NS) } \\
\hline 2 & 12 & 31.5 & 8 & 23.5 & \\
\hline 3 & 8 & 21 & 2 & 5.8 & \\
\hline 4 & 0 & 0 & 2 & 5.8 & \\
\hline Rt. Lobe & 28 & 73.6 & 26 & 76.4 & \multirow{4}{*}{0.24 (NS) } \\
\hline Lt. Lobe & 8 & 21 & 4 & 11.7 & \\
\hline Not done & 2 & 5.2 & 6 & 17.6 & \\
\hline $\begin{array}{c}\text { Non } \\
\text { visualized }\end{array}$ & 2 & 5.2 & 4 & 11.7 & \\
\hline Diameter & \multicolumn{2}{|c|}{$3.21 \pm 1.1 \mathrm{~cm}$} & \multicolumn{2}{|c|}{$3.0 \pm 1.3 \mathrm{~cm}$} & 0.61 (NS) \\
\hline \multicolumn{6}{|c|}{ Enhancement } \\
\hline Typical & 32 & 84 & 24 & 70.5 & \multirow{2}{*}{0.36 (NS) } \\
\hline Atypical & 4 & 10.4 & 6 & 17.6 & \\
\hline
\end{tabular}

The background characteristics were comparable in both $\mathrm{RFA}+\mathrm{S}$ and RFA groups; F:M ratio was 0:40 and 2:38 ( $\mathrm{P}>0.5)$, with a mean age of $52.6+9$ and $58.4+5.9(\mathrm{P}=0.02)$ respectively. The tri-phasic CT assessment pre-procedure showed that there was no statistically significant difference between the two groups regarding number, diameter or enhancement of HCC lesions Table 1. Typical enhancement was shown in 32/36 (89\%) in the RFA+S compared to $24 / 30$ (80\%) in the RFA group. Tri- phasic $\mathrm{CT}$ was not done in 2 patients in RFA+S group and six from RFA group (diagnosed by tru-cut biopsy).

The histo-pathological grading was comparable in both groups; HCC grade I was found in $26(65 \%)$, grade II in $8(20 \%)$, grade I-II in $4(10 \%)$, grade II-III in $2(5 \%)$ of the RFA+S, compared to grade I in $32(80 \%)$ and grade II in $7(15 \%)$ of the RFA group. While one patient showed dysplasia only (RFA group) but with typical enhancement shown on tri- phasic CT. He was diagnosed as HCC according to our definition and included in our intervention.

\section{Biochemical response}

Table 2: Biochemical profile before and one week after procedure in both groups.

\begin{tabular}{|c|c|c|c|c|c|c|}
\hline \multirow{2}{*}{ Item } & \multicolumn{2}{|c|}{ RFA+S } & \multirow{2}{*}{ P Value } & \multicolumn{2}{|c|}{ RFA } & \multirow{2}{*}{ P Value } \\
\hline & Before & After & & Before & After & \\
\hline Bill. & $\begin{array}{c}1.24 \pm \\
0.87\end{array}$ & $\begin{array}{c}1.8 \\
\pm 1.2\end{array}$ & $0.010(\mathrm{~S})$ & $\begin{array}{c}1.34 \\
\pm 1.16\end{array}$ & $\begin{array}{c}1.24 \\
\pm 0.88\end{array}$ & 0.629 \\
\hline AST & $\begin{array}{l}73.78 \\
\pm 27.4\end{array}$ & $\begin{array}{c}99.5 \\
\pm 67.8\end{array}$ & 0.104 & $\begin{array}{l}83.18 \\
\pm 46.3\end{array}$ & $\begin{array}{l}65.47 \\
\pm 32.7\end{array}$ & 0.086 \\
\hline ALT & $\begin{array}{c}84.5 \\
\pm 42.04\end{array}$ & $\begin{array}{c}70.5 \\
\pm 52.4\end{array}$ & 0.351 & $\begin{array}{l}71.1 \\
\pm 37\end{array}$ & $\begin{array}{r}66.88 \\
\pm 36.4\end{array}$ & 0.715 \\
\hline ALP & $\begin{array}{c}310.44 \pm \\
140.5\end{array}$ & $\begin{array}{c}315 \\
\pm 172.8\end{array}$ & 0.929 & $\begin{array}{l}293.1 \\
\pm 92.6\end{array}$ & $\begin{array}{l}277.9 \\
\pm 65.4\end{array}$ & 0.61 \\
\hline $\mathrm{TP}$ & $\begin{array}{c}7.22 \\
\pm 0.414\end{array}$ & $\begin{array}{l}7.67 \\
\pm 1.0\end{array}$ & 0.125 & $\begin{array}{c}7.1 \\
\pm 0.49\end{array}$ & $\begin{array}{c}6.9 \\
\pm 0.51\end{array}$ & 0.125 \\
\hline ALB & $\begin{array}{c}3.56 \\
\pm 0.314\end{array}$ & $\begin{array}{c}3.1 \\
\pm 0.79\end{array}$ & $0.042(S)$ & $\begin{array}{c}3.48 \\
\pm 0.38\end{array}$ & $\begin{array}{c}3.16 \\
\pm 0.31\end{array}$ & $0.004(\mathrm{~S})$ \\
\hline PC & $\begin{array}{c}77.3 \\
\pm 12.2\end{array}$ & $\begin{array}{l}79.5 \\
\pm 8.9\end{array}$ & 0.626 & $\begin{array}{c}70.1 \\
\pm 9\end{array}$ & $\begin{array}{l}69.5 \\
\pm 8.8\end{array}$ & 0.686 \\
\hline
\end{tabular}

The liver biochemical profile in both groups before and one week after RFA showed a statistically significant elevation of serum bilirubin post procedure in the RFA+S group compared to pre-procedure level $(\mathrm{P}=0.010)$. Serum albumin showed a significant decrease post-procedure in both groups $(\mathrm{P}=0.042$ $\&$ 0.004) respectively. There was no statistically significant difference in ALT, AST, ALP or AFP in both groups pre and post procedures (Table 2). However, AFP level markedly decreased one month post procedure in the RFA+S compared to the RFA group (the pre/post procedure mean \pm SD was $976+2414.5 \mathrm{ng} / \mathrm{dl}$ and $546.9+1157.8 \mathrm{ng} / \mathrm{dl}$ vs322.4+696.3ng/ $\mathrm{dl}$ and $760.4+1982.8 \mathrm{ng} / \mathrm{dl}$ ) respectively, but the difference was not statistically significant. Interestingly, $56 / 80$ of our patients (70\%) had AFP levels below 200ng/dl. 


\section{The RFA machine parameters during procedure}

Table 3: RFA procedure details in both groups.

\begin{tabular}{|c|c|c|c|}
\hline Item & $\mathrm{RFA}+\mathrm{S}$ & RFA & $P$ value \\
\hline \multicolumn{4}{|c|}{ Number of Cycles } \\
\hline $1 \mathrm{x} 13 \mathrm{~min}$ & 26 & 24 & \multirow{4}{*}{$\begin{array}{l}0.5 \text { (NS) } 1.0 \\
\quad(\mathrm{NS})\end{array}$} \\
\hline $2 \times 13 \min$ & 12 & 16 & \\
\hline $3 \times 13 \min$ & 2 & 0 & \\
\hline Total duration & $18.2 \pm 7.7$ & $18.2 \pm 6.5$ & \\
\hline \multicolumn{4}{|c|}{ Pulsing } \\
\hline$<1$ min & 8 & 36 & \multirow{5}{*}{$0.001(\mathrm{HS})$} \\
\hline $1-2 \min$ & 12 & 0 & \\
\hline 3-4 min & 8 & 0 & \\
\hline$>4 \min$ & 2 & 0 & \\
\hline no pulsing & 10 & 4 & \\
\hline
\end{tabular}

The RFA procedure details in both groups are tabulated in (Table 3). Most of the patients had one cycle (13 minutes duration of RFA application) in each session (26 patients in RFA+S group and 24 patients in RFA group). The difference in number of cycles (13 minutes) per session was not statistically significant in both groups. $(\mathrm{P}=0.5)$. All the $\mathrm{RFA}+\mathrm{S}$ patients necessitated one session only (40/100\%) compared to (36/90\%) in the RFA group), as 4 patients in the later had a second session after one month because of the persistence of $50 \%$ viable cells on FNAC post procedure (Table 3). The pulsing (repeated cut off) in the $\mathrm{RFA}+\mathrm{S}$ group occurred mostly in a frequency more than one minute in $32(80 \%)$ to the extent that 10 of the 32 patients had no pulsing at all (continuous energy deposition all-through the 13 minutes), while in the RFA group, most of the patients 36 $(90 \%)$ had pulsing in a frequency less than one minute (Table 3$).$ Such results were statistically highly significant $(\mathrm{P}=0.01)$.
Table 4: RF machine parameters during application of RF in both groups.

\begin{tabular}{|c|c|c|c|c|c|}
\hline Item & Group & N & Mean & SD & P value \\
\hline \multirow{2}{*}{$\begin{array}{c}\text { Minimum } \\
\text { impedance }\end{array}$} & $\mathrm{RFA}+\mathrm{S}$ & 26 & 57.23 & 9.11 & \multirow{2}{*}{$0.024(\mathrm{~S})$} \\
\cline { 2 - 5 } & $\mathrm{RFA}$ & 24 & 67.50 & 11.73 & \\
\hline $\begin{array}{c}\text { Maximum } \\
\text { Impedance }\end{array}$ & $\mathrm{RFA}+\mathrm{S}$ & 26 & 77.08 & 14.98 & \multirow{2}{*}{$0.027(\mathrm{~S})$} \\
\cline { 2 - 5 } $\begin{array}{c}\text { Mean } \\
\text { Impedance }\end{array}$ & $\mathrm{RFA}$ & 24 & 100.50 & 29.94 & \\
\cline { 2 - 5 } & $\mathrm{RFA}+\mathrm{S}$ & 26 & 67.15 & 11.13 & \multirow{2}{*}{$0.017(\mathrm{~S})$} \\
\hline \multirow{2}{*}{$\begin{array}{c}\text { Current } \\
\text { Maximum } \\
\text { Temperature }\end{array}$} & $\mathrm{RFA}+\mathrm{S}$ & 24 & 84.00 & 19.36 & \\
\cline { 2 - 5 } & $\mathrm{RFA}$ & 24 & 1.46 & .23 & \multirow{2}{*}{$0.018(\mathrm{~S})$} \\
\cline { 2 - 5 } & $\mathrm{RFA}+\mathrm{S}$ & 26 & 26.54 & 7.05 & \multirow{2}{*}{$0.069(\mathrm{NS})$} \\
\hline $\begin{array}{c}\text { Minimum } \\
\text { Temperature }\end{array}$ & $\mathrm{RFA}+\mathrm{S}$ & 26 & 32.67 & 8.76 & \\
\cline { 2 - 5 } & $\mathrm{RFA}$ & 24 & 20.75 & 3.98 & \\
\hline \multirow{2}{*}{$\begin{array}{c}\text { Mean } \\
\text { Temperature }\end{array}$} & $\mathrm{RFA}+\mathrm{S}$ & 26 & 22,54 & 5.60 & \multirow{2}{*}{$0.086(\mathrm{NS})$} \\
\cline { 2 - 5 } & $\mathrm{RFA}$ & 24 & 26.71 & 5.99 & \\
\hline
\end{tabular}

The RF machine parameters during RF application in both groups showed that the minimum impedance (tissue resistance), maximum impedance and mean impedance were lower in RFA+S group than RFA group and this was statistically significant. The current (energy deposition leading to coagulative necrosis) was higher in RFA $+S$ group than RFA group and this was statistically significant (Table 4). The minimum temperature (around the needle), maximum temperature and mean temperature were lower in RFA+S group than in RFA group, but this was statistically insignificant. In RFA+S group, the pulsing frequency was not affected by the diameter of the focal lesion. (p: 0.87) but the total duration of application was directly proportionate to the diameter of the focal lesion (Table 5). As it was noticed that when the diameter increases the duration of application of RF increases to obtain a larger diameter of coagulation and ensure total ablation of the larger focal lesion with a good safety margin around, and this was statistically significant $(p=0.003)$. In RFA group; Table 6 neither the pulsing frequency nor the total duration of application of RF was affected by the diameter of focal lesion.

Table 5: The relation between pulsing frequencies, total duration of RFA and tumor diameter in the RFA+S group.

\begin{tabular}{|c|c|c|c|c|c|c|c|}
\hline & Diameter & $\mathbf{N}$ & Mean & SD & Minimum & Maximum & P Value \\
\hline \multirow{4}{*}{ Pulsing frequency } & $<3$ & 20 & 2.40 & 1.56 & $/ 0.50 \mathrm{~min}$ & $/ 5.00 \mathrm{~min}$ & \multirow{4}{*}{$0.112(\mathrm{NS})$} \\
\hline & $3.1-4$ & 16 & 1.25 & 1.16 & $0.00 \mathrm{~min}$ & $/ 3.00 \mathrm{~min}$ & \\
\hline & 4.1-5 & 4 & 1.00 & 1.41 & 0.0 & $/ 2.00$ & \\
\hline & Total & 40 & 1.89 & 1.48 & 0.00 & 5.00 & \\
\hline \multirow{4}{*}{ Total duration of application } & $<3$ & 20 & 13.00 & 0.00 & $13.00 \mathrm{~min}$ & $13.00 \mathrm{~min}$ & \multirow{4}{*}{$0.003(\mathrm{HS})^{*}$} \\
\hline & $3.1-4$ & 16 & 24.38 & 8.33 & $13.00 \mathrm{~min}$ & $39.00 \mathrm{~min}$ & \\
\hline & 4.1-5 & 4 & 26.00 & & $26.00 \mathrm{~min}$ & $26.00 \mathrm{~min}$ & \\
\hline & Total & 40 & 18.47 & 7.89 & $13.00 \mathrm{~min}$ & $39.00 \mathrm{~min}$ & \\
\hline
\end{tabular}




\section{The success of RFA procedures in both groups}

Table 6: The relation between pulsing frequency, total duration of RFA and tumor diameter in the group.

\begin{tabular}{|c|c|c|c|c|c|c|c|}
\hline & Diameter & $\mathbf{N}$ & Mean & SD & Minimum & Maximum & \multirow{5}{*}{$\begin{array}{c}\text { P value } \\
0.87 \text { (NS) }\end{array}$} \\
\hline \multirow{4}{*}{ Pulsing frequency } & $<3$ & 24 & 0.6583 & 0.3777 & $/ 0.00 \mathrm{~min}$ & $/ 1.00 \mathrm{~min}$ & \\
\hline & $3.1-4$ & 8 & 0.6250 & 0.2500 & $/ 0.50 \mathrm{~min}$ & $/ 1.00 \mathrm{~min}$ & \\
\hline & $4.1-5$ & 8 & 0.5000 & 0.5000 & $/ 0.00$ & $/ 1.00 \mathrm{~min}$ & \\
\hline & Total & 40 & 0.6263 & 0.3588 & $/ 0.00$ & $/ 1.00 \mathrm{~min}$ & \\
\hline \multirow{4}{*}{ Total duration of application } & $<3$ & 24 & 18.4167 & 6.6941 & $13.00 \mathrm{~min}$ & $26.00 \mathrm{~min}$ & \multirow{4}{*}{$0.56(\mathrm{NS})$} \\
\hline & $3.1-4$ & 8 & 16.2500 & 6.5000 & $13.00 \mathrm{~min}$ & $26.00 \mathrm{~min}$ & \\
\hline & $4.1-5$ & 8 & 21.6667 & 7.5056 & $13.00 \mathrm{~min}$ & $26.00 \mathrm{~min}$ & \\
\hline & Total & 40 & 18.4737 & 6.5943 & $13.00 \mathrm{~min}$ & $26.00 \mathrm{~min}$ & \\
\hline
\end{tabular}

Table 7: Success rate in both groups.

\begin{tabular}{|c|c|c|c|c|}
\hline Item & RFA+S & & RFA & \\
\hline & No & \% & No & \% \\
\hline Final results: & 40 & 100 & 22 & 55 \\
Successful & 0 & 0 & 18 & 45 \\
Failure with shift to PEI & 40 & 100 & 16 & 44 \\
\hline Depending on Triphasic CT: & 0 & 0 & 20 & 56 \\
Ablation & 36 & 100 & 14 & 43.7 \\
No /partial ablation & 0 & 0 & 18 & 56.3 \\
\hline Depending on pathology: & & & & \\
\hline Complete ablation & $40(100 \%)$ & $40(100 \%)$ \\
\hline No ablation & Total &
\end{tabular}

Complete ablation was achieved in all $40(100 \%)$ of the RFA+S compared to $16 / 36(44.4 \%)$ in the RFA group $(\mathrm{P}<0.01)$ Table 7. Partial ablation was obtained in 16/36(44.4\%) of RFA group and the remaining $4 / 36(11 \%)$ had no ablation at all. According to the histo-pathological findings post treatment; the success rate was $100 \%(36 / 36)$ in the RFA+S compared to $43.7 \%(14 / 32)$ in the RFA group Table 7. Four patients from RFA group showed complete ablation by the tri- phasic CT but biopsy was not done for them, another four patients showed $50 \%$ viable malignant cells in tru-cut biopsy after procedure, so another session of RFA alone was repeated and complete ablation was obtained. The final success rate in RFA group reached $(14+4+4=22)$ $22 / 40(55 \%)$. The remaining eighteen $(45 \%)$ patients of RFA group were shifted to percutaneous ethanol injection (PEI). This difference between both groups was statistically highly significant. $(\mathrm{P} \leq 0.01)$

\section{RFA procedure related complications}

The procedure related early complications showed that abdominal pain during session was the most encountered problem. It was sometimes associated with shoulder pain in focal lesions of Rt. lobe near the diaphragm. The pain was relieved by
I.V analgesics. Thigh burn (hyperemia) occurred in two patients (5\%) in each group that was related to the cluster needle Table 8 . In the next 2 hours post procedure; 2 patients in the RFA+S group had fever (transient and relieved by antipyretics). None of the patients of RFA group experienced fever. Late complications included abscess formation, biloma, subphrenic collection, and ascites Table 8. The abscess and subphrenic collection responded to repeated aspirations. The ascites was moderate and responded to diuretics. None of both groups had any remote complications. The difference in frequency of occurrence of any complication (during, early, late and remote) in both groups was statistically insignificant.

Table 8: Procedure related complications in both groups.

\begin{tabular}{|c|c|c|c|c|c|}
\hline Item & \multicolumn{2}{|c|}{$\mathrm{RFA}+\mathrm{S}$} & RFA & & $\begin{array}{c}P \\
\text { value }\end{array}$ \\
\hline \multirow[t]{2}{*}{$\begin{array}{l}\text { Complications during } \\
\text { procedure: } \\
\text { i. Abdominal pain } \\
\text { ii. Thigh burn } \\
\text { iii. Non }\end{array}$} & No & $\%$ & No & $\%$ & \multirow[t]{2}{*}{$\begin{array}{c}0.78 \\
\text { NS }\end{array}$} \\
\hline & $\begin{array}{c}28 \\
2 \\
10\end{array}$ & $\begin{array}{c}70 \\
5 \\
25\end{array}$ & $\begin{array}{c}24 \\
2 \\
14\end{array}$ & $\begin{array}{c}60 \\
5 \\
35\end{array}$ & \\
\hline $\begin{array}{c}\text { Early complications }\left(1^{\text {st }} .24 \mathrm{~h}\right) \\
\text { i. Non } \\
\text { ii. Fever }\end{array}$ & $\begin{array}{c}38 \\
2\end{array}$ & $\begin{array}{c}95 \\
5\end{array}$ & $\begin{array}{c}40 \\
0\end{array}$ & $\begin{array}{c}100 \\
0\end{array}$ & $\begin{array}{l}0.37 \\
\text { NS }\end{array}$ \\
\hline $\begin{array}{l}\text { Late complications (within } \\
\text { 2months) } \\
\text { Non Abscess formation } \\
\text { Ascites } \\
\text { Subphrenic collection } \\
\text { Biloma }\end{array}$ & $\begin{array}{c}35 \\
2 \\
2 \\
0 \\
1\end{array}$ & $\begin{array}{c}87.5 \\
5 \\
5 \\
0 \\
2.5\end{array}$ & $\begin{array}{c}37 \\
0 \\
2 \\
1 \\
0\end{array}$ & $\begin{array}{c}92.5 \\
0 \\
5 \\
2.5 \\
0\end{array}$ & $\begin{array}{c}0.36 \\
\text { NS }\end{array}$ \\
\hline $\begin{array}{l}\text { Remote complications (after } \\
\qquad 2 \mathrm{~m} \text { ) }\end{array}$ & 0 & 0 & 0 & 0 & \\
\hline
\end{tabular}




\section{Follow up (post RFA)}

Twenty four month follow up of RFA+S group showed that $2(5 \%)$ had recurrence at the site of ablated tumor one year after ablation, $12(30 \%)$ had De novo lesions (new lesions elsewhere in the liver), $2(5 \%)$ had liver abscess early in the follow up at the site of ablated tumor and one (2.5\%) developed biloma. Ascites developed in $8(20 \%)$ mostly after one year (unrelated to the RF procedure). None of both groups had PV thrombosis, jaundice worsening or hepatic encephalopathy. The median event free time (EVF) for RFA+S group was 14 months. The event free rate was $35 \%$ while the cancer free rate was $60 \%$. Three (7.5\%) patients dropped during follow up period Table 9. In the RFA group, 18 patients were shifted to PEI after failure of the RF procedure and were not included in our follow up. The successful RFA 22 patients followed up for 24 month. Two (11\%) had primary recurrence after 14 months of ablation, 10(55.5\%) developed De novo lesions in the liver mostly within the first year of follow up. Two (11\%) had PV thrombosis after 7 and 9 months respectively and two had ascites. None of the patients had jaundice worsening, hepatic encephalopathy or liver abscess Table 9.

Table 9: Frequency of complications and follow-up in the successful cases of both groups.

\begin{tabular}{|c|c|c|c|c|c|}
\hline Finding & \multicolumn{2}{|c|}{ RFA+S } & \multicolumn{2}{|c|}{ RFA } & P value \\
\hline $\begin{array}{c}\text { Primary } \\
\text { recurrence }\end{array}$ & 2 & $5 \%$ & 2 & $11 \%$ & $0.99(\mathrm{NS})$ \\
\hline De novo lesions & 12 & $30 \%$ & 10 & $55.50 \%$ & $0.25(\mathrm{NS})$ \\
\hline PV thrombosis & 0 & 0 & 2 & $11 \%$ & $0.31(\mathrm{NS})$ \\
\hline Ascites & 8 & $20 \%$ & 2 & $11 \%$ & $0.99(\mathrm{NS})$ \\
\hline Liver abscess & 2 & $5 \%$ & 0 & 0 & $0.99(\mathrm{NS})$ \\
\hline Biloma & 1 & $5 \%$ & 0 & 0 & $0.99(\mathrm{NS})$ \\
\hline $\begin{array}{c}\text { Procedure } \\
\text { success }\end{array}$ & 14 & $35 \%$ & 4 & $44 \%$ & $0.69(\mathrm{NS})$ \\
\hline $\begin{array}{c}\text { Cancer free } \\
\text { success }\end{array}$ & 24 & $60 \%$ & 4 & $44 \%$ & $0.69(\mathrm{NS})$ \\
\hline
\end{tabular}

The procedure success was $44.4 \%$ and the cancer free rate was $44.4 \%$. The event free time (EVF) for the RFA group was one month (As nine patients shifted to PEI). Two patients dropped out during the follow up period. However, the difference between both groups in the follow up parameters was not statistically significant

By Binary logistic regression analysis, there was no significant impact of age, site / size of focal lesion or duration of the procedure on the final outcome of our patients.

\section{Discussion}

Considerable interest has developed, during the last 10 years, in the thermal ablation techniques as RFA for treatment of HCC. Differences in reported success rates are definitely multi factorial and include patient selection, operator experience, and equipment used [10]. One of the used strategies to increase the ablation volume in RFA is intra- tumoral saline injection prior to or during RFA application aiming at changing the environment of HCC cells.

Livraghi et al. [11] hypothesized three potential effects to explain the substantial increase in the volume of necrosis that was achieved with saline enhancement:

a) increase of the effective surface area of the RF electrode (originally believed to be the only effect),

b) tissue cooling or decreased tissue impedance leading to improved tolerance of increased generator output, and

c) boiling saline diffusion into the tissues.

Also, two mechanisms have been proposed by Goldberg et al. [7] to account for the increased RF-induced coagulation with saline infusion: $\mathrm{NaCI}$ alters tissue properties such as electrical conductivity to permit greater RF energy deposition [1], or [2] the infusion of fluid improves the thermal conduction within the tissues by more rapidly and effectively producing heat convection over a larger tissue volume.

To our knowledge, this is the first study aiming to evaluate, in details, the changes in RF machine parameters after combined saline intra-tumor injection for ablation of HCC in HCV patients. Our RF machine was set on the impedance control system. In other words, the machine is automatically set to change its current (energy deposition) according to the impedance recorded at the tip of the needle. So, when the impedance is low, the current is at its maximum (maximum energy deposition) and when the impedance rises (due to tissue coagulation) the current decreases or even stops to prevent the occurrence of charring at the tip until the impedance decreases again (taking seconds to one minute) then the current rises automatically. According to meta-analysis and other previous studies in the field of RFA in HCC; it was shown that cool-tip RFA with impedance control associated with saline could be the best method to obtain complete coagulation of the tumor and achieve $100 \%$ success rate, and this exactly what our machine parameters actually confirmed in this study.

The RF machine parameters in our study showed that the impedance (minimum, maximum and mean) and the temperature (minimum, maximum and mean) were significantly lower in RFA+S group than RFA group, the current was significantly higher in RFA+S group than RFA group. These results agreed with Goldberg et al. [7] who studied the effects of $\mathrm{NaCl}$ injection on tissue electrical conductivity, RF deposition and heating in agar phantoms in in-vivo models. They recorded that $\mathrm{NaCl}$ solution injection prior to $\mathrm{RF}$ had significant effects on electrical conductivity, RF deposition and heating of agar phantoms. Also they recorded significant increase in generator output (increased current), marked tissue heating /coagulation and significant decrease in tissue impedance.

They recorded maximum heating $20 \mathrm{~mm}$ from the electrode and maximum coagulation $(7.1 \mathrm{~cm})$ for $\mathrm{RF}$ application after the 
injection of $\mathrm{NaCl}$ which resulted in nearly twofold increase in coagulation diameter when compared with RF alone. Livraghi et al. [11] conducted several experiments using 18-gauge needle electrodes and continuous saline infusion $(1 \mathrm{~mL} / \mathrm{min})$ during RFA in ex vivo models and in vivo animals and humans (15 patients with liver metastases). They proved the efficacy of saline-enhanced RFA in producing large volumes of necrosis up to $3.9 \mathrm{~cm}$. Miao et al. [12] reported necrosis of lesions larger than $5.5 \mathrm{~cm}$ with saline enhanced RFA in rabbits liver tumors.

In our study, the pulsing in the RFA+S group occurred mostly in a frequency more than one minute, while in the RFA group most of the patients had pulsing in a frequency less than one minute. This could be explained by the decreased impedance with intra- tumoral saline injection; as with the presence of saline around the tip of the needle, the temperature is lowered (as recorded in our results) and the charring around the needle is prevented, this decreases the frequency of bouts of increased impedance (associated with decreased generator output), so energy deposition (and subsequently tissue necrosis) occurs during most of the 13 minutes cycle.

We could not find another research studying this parameter in the RF machine when applied for HCC ablation. But we believe this parameter is important as it determines the "actual" energy and heat deposited in the tumor during the 13 minutes cycle. The total duration of application (number of cycles) of RFA, in our study, was found to be directly proportionate to the diameter of the focal lesion in the RFA+S group but not in the RFA group and this difference was statistically significant. This difference between the two groups could be explained, as with the intratumor saline injection, the impedance is lowered and the current increased (as recorded in the RFA+S group), so the operator is encouraged to prolong or repeat the cycle of RFA as he feels that the session will yield a promising result (complete ablation). In contrast; in RFA group, having a high impedance and low current made the operator feels that the RF is not effective so he is not encouraged to prolong or repeat the cycle.

Our success rate, in the RFA+S group, was superior to the results of Livraghi et al. [11] using RFA enhanced with saline injection in 25 metastatic focal lesions, they achieved complete necrosis in $52 \%$ of lesions. Also our results were superior to the results obtained by Kettenbach et al. [13] who studied percutaneous saline enhanced RF in twenty six patients with 15 HCC and 33 hepatic metastasis. In their study, incomplete ablation was recorded in 35\%. Kettenbach et al. [13] also recorded that tumors of $3 \mathrm{~cm}$ or less in diameter had eight times chance to be completely ablated with success. Favorable treatment results were most likely due to the creation of adequate "surgical" margins surrounding the tumor, so such margins are more likely to be obtained in smaller lesions.

This difference between our results and the results of the above 2 studies could be due to the difference in the nature of tumor (HCC vs. metastasis) due to the biologic peculiarity, the difference in the technique of RF, as Livraghi et al. [11] used the conventional single needle (not the cool-tip) with continuous saline infusion. So, it is well known that the original method ablates smaller lesions than the cool-tip. Also the continuous saline infusion produces irregular shape of ablation.

Also, in the study by Kettenbach et al. [13] they used a needle with $1.5 \mathrm{~cm}$ conductive portion at the tip, but in our study we used the $3 \mathrm{~cm}$ conductive portion needle thus producing larger diameter of coagulation. Similar to our study, Livraghi et al. [11] used feedback control of the impedance in the tissue, which allows the regulation of the power output to keep the impedance below a threshold value and provide automatic heat regulation in the targeted area. However, they added automatic modification of the flow rate of continuous saline infusion during RFA to keep low impedance in tissues, thus avoiding desiccation and subsequent carbonization in the targeted area.

Our results were nearly the same as the results obtained by Giorgio et al. [14] in lesions less than $3 \mathrm{~cm}$; they studied saline enhanced RF in 84 patients with HCC having 95 lesions. They obtained $95 \%$ success rate in lesions less than $3 \mathrm{~cm}$ in diameter. But in lesions $3-5 \mathrm{~cm}$ in diameter, in Giorgio et al. [14] study, the success rate was $71 \%(39 / 45)$ and in lesions $>5 \mathrm{~cm}$ the success rate was $12.5 \%(1 / 8)$. So, our results did not match study regarding lesions larger than $3 \mathrm{~cm}$ as we achieved $100 \%$ success rate in such cases $(20 / 20)$.

Moreover, the low rate of complete necrosis in larger $(>3.0 \mathrm{~cm}) \mathrm{HCC}$ lesions in our RFA only group $(50 \%)$ confirms the lack of efficacy of RFA as the sole treatment in these tumors. Combination with other therapies (i.e., saline, TACE or percutaneous ethanol injection) should be considered. It appears also that combined normal saline with RFA, in our study, was more superior than hypertonic saline enhanced RFA (RFA+HS), as in the study done by El-Kady et al. [9], tri- phasic CT, one month after RFA+HS showed that 17 (85\%) patients achieved complete ablation, whereas $3(15 \%)$ achieved partial ablation. Moreover, 12/13 (92\%) of medium HCC and 5/7 (71\%) of large HCC were successfully ablated. The relation between success rate and lesion diameter was significant. After 6 months, $73.7 \%$ of patients who underwent RFA+HS showed maintained ablation.

With review of studies treating malignancy with combined RFA and hypertonic saline, only one other study reported combined RFA with hypertonic saline in humans and was done on pulmonary metastatic tumor (from HCC) in one patient [15]. Other studies were done in animals like rabbit liver $[12,16]$ or kidney [17] or porcine liver [18] or done in explanted bovine liver [19-21] and all showed that RFA+HS gave better efficiency in creating a large ablation area than does dry RFA. The post procedural complications in our study were comparable between both groups, indicating higher ablation with no additional harmful effects. But we slightly disagreed with Moriyasu [22] who said that biloma does not occur with RFA, 
because the process of RFA is strongly moderated by blood flow and heat conduction, the zone of ablation is both predictable and controllable and the ablation process is less damaging than the direct microwave energy or alcohol. But apparently, in our study, with addition of saline, this rule has changed.

The abscess and the biloma recorded, in our study, were met with when the amount of saline increased significantly in relation to the tumor diameter (about 15 to $20 \mathrm{cc}$ saline in each tumor). The relatively large amount of saline had led to the creation of a large area of coagulation larger than the tumor itself associated with liquefaction and eventually infection on top. Also our results didn't agree with Giorgio et al. [23] who reported complications that occurred with saline-enhanced RFA in primary or metastatic liver tumors. The number of patients with major complications, including death, was three $(0.9 \%)$. The overall mortality rate was $0.3 \%(1 / 336)$. One patient died because of worsening liver decomposition. Two other major complications occurred; liver abscess and sepsis that developed in one patient $(0.3 \%)$. Mild post-treatment ascites occurred in one $(0.3 \%)$. One patient showed self-limiting subcutaneous cellulitis along the electrode path. Fever lasting 1-3 days and pain lasting 12-24 hours were observed in 141 patients (42\%) and 211 patients (63\%), respectively. Another work by Boehm et al. [24] compared saline enhancement versus internallycooled RFA electrode for the treatment of small carcinomas of the breast in a rabbit model. The authors found the two methods to be equally efficacious but encountered a significantly higher complication rate with the saline technique.

In the follow up of our patients, our results (in $\mathrm{RFA}+\mathrm{S}$ group) were in agreement with Huang et al. [25] as they recorded primary recurrence in $2.7 \%$ and secondary recurrence in $33.6 \%$. But in RFA group, we obtained higher secondary recurrence rate not corresponding to Huang et al study. Also, in the RFA+S group, we obtained $60 \%$ cancer free success rate which was in agreement with who recorded that $72 \%$ of patients remained tumor free for a median follow up period of 15 months, but in RFA group, we obtained lower results (44.4\%) than.

In spite of these encouraging results, the RFA plus saline technique was neglected in favor of other forms of radiofrequency ablation because of the irregular shape of the zone of tissue necrosis and the difficulty in expecting the size of ablation. However, similar problems are encountered occasionally with other thermo-ablation techniques. For instance, incomplete and irregular necrosis due to the cooling effect of large vessels situated near the margin of the treated lesion have been described with all RFA devices and with interstitial laser photocoagulation.

\section{Conclusion}

In conclusion, when augmentation with intra-tumor saline occurs, the success rate of cool-tip RFA increases to $100 \%$ with great safety and no increase in complications even in large tumors $(3-5 \mathrm{~cm})$. As saline is easily accessible and the intratumor injection is an easy technique; this increase in success rate could be very promising in future approaches to improve the RFA technique. Combined saline and RFA should be widely used in ablation of HCC in cirrhotic patients as it is safe, highly effective, one session technique, non-costly and easy to perform.

\section{Acknowledgement}

The authors would like to thank Nabeel El- Kady, professor of Hepato- gastroenterology and Endemic Medicine department, Faculty of Medicine, Cairo University.

\section{Funding}

This research did not receive any specific grant from any funding agency in the public, commercial or not-for-profit sector.

\section{References}

1. Mohamed M, Rakha M, Shoei S, Saber M (1996) Viral hepatitis C among Egyptians: The magnitude of the problem: Epidemiological and laboratory approach. J Egypt Public Health Assoc 71(1-2): 79-111.

2. Zakaria S, El Raziky M, Fouad R, et al. (2000) Seroprevalence of viral hepatitis markers in a rural and semi rural Egyptian district. Antiviral Therapy 5(1): F12.

3. Esmat G (2002) Hepatocellular carcinoma: The magnitude of the problem in Egypt, 6th international conference of oncology, surgery and gastroenterology. Towards a Healthy Liver in Egypt 10-12: 54.

4. Jones S (1999) Cancer in the developing world: a call to action. BMJ Middle East 319(7208): 505-508.

5. Goldberg SN, Kruskal JB, Oliver BS, Clouse ME, Gazelle GS (2000) Percutaneous tumor ablation: increased coagulation by combining radio-frequency ablation and ethanol instillation in a rat breast tumor model. Radiology 217(3): 827-831.

6. Goldberg SN, Saldinger PF, Gazelle GS, Huertas JC, Stuart KE, et al. (2001) Percutaneous tumor ablation: increased necrosis with combined radiofrequency ablation and intratumoral doxorubicin injection in a rat breast tumor model. Radiolog 220(2): 420-427.

7. Goldberg SN, Ahmed M, Gazalle S, Kruskal JB, Huertas JC, et al. (2001) Radiofrequency thermal ablation with $\mathrm{NaCl}$ solution injection: Effect of electrical conductivity on tissue heating and coagulation - phantom and porcine liver study. Radiology 219(1):157-165.

8. Bloomston M, Binitie O, Fraiji E (2002) Transcatheter arterial chemoembolization with or without radiofrequency ablation in the management of patients with advanced hepatic malignancy. Am Surg 68(9): 827- 831.

9. El Kady NM, Esmat G, Mahmoud EH, Darweesh SK, Mahmoud SH, et al. (2012) Hypertonic saline-enhanced radiofrequency versus chemoembolization sequential radiofrequency in the treatment of large hepatocellular carcinoma. Eur J Gastroenterol Hepatol 25(5): 628-633.

10. McGahan JP, Dodd GD (2001) Radiofrequency ablation of the liver: Current status. AJR Am J Roentgenol 176(1): 3-16.

11. Livraghi T, Goldberg SN, Monti F (1997) Saline-enhanced radiofrequency tissue ablation in the treatment of liver metastases. Radiology 205(2): 582-584.

12. Miao Y, Ni Y, Mulier S, Yu J, De Wever I (2000) Treatment of VX2 liver tumor in rabbits with "wet" electrode mediated radiofrequency ablation. Eur Radiol 10(1):188-194.

13. Kettenbach J, Kostler W, Rucklinger E, Gustorff B, Hüpfl M, et al. (2003) Percutaneous saline- enhanced radiofrequency ablation of unresectable hepatic tumors: initial experience in 26 patients. A J R $180(6): 1537-45$. 
14. Giorgio A, Tarantino L, De Stefano G, Scala V, Liorre G, et al. (2003) Percutaneous sonographically guided saline-enhanced radiofrequency ablation of hepatocellular carcinoma. AJR Am J Roentgenol 181(2): 479-484.

15. Kim TS, Lim HK, Kim H (2006) Excessive hyperthermic necrosis of a pulmonary lobe after hypertonic saline-enhanced monopolar radiofrequency ablation. Cardiovasc Intervent Radiol 29(1): 160-163.

16. Lee JM, Kim YK, Lee YH, Kim SW, Li CA, et al. (2003) Percutaneous Radiofrequency Thermal Ablation with Hypertonic Saline Injection: In Vivo Study in a Rabbit Liver Model. Korean J Radiol 4(1): 27-34.

17. Munver R, Threatt CB, Delvecchio FC, Preminger GM, Polascik T] (2002) Hypertonic saline-augmented radiofrequency ablation of VX2 tumor implanted in rabbit kidney: a short-term survival pilot study. Urology 60: 170-175.

18. Burdío F, Güemes A, Burdío JM, Navarro A, Sousa R, et al. (2003) Bipolar saline-enhanced electrode for radiofrequency ablation: results of experimental study of in vivo porcine liver. Radiology 229(2): 447-456.

19. Lee JM, Han JK, Kim SH, Sohn KL, Lee KH, et al. (2003) A comparative experimental study of the in-vitro efficiency of hypertonic salineenhanced hepatic bipolar and monopolar radiofrequency ablation Korean J Radiol 4(3):163-169.
20. Lee JM, Han JK, Kim SH, Lee JY, Choi SH, et al. (2004) Hepatic bipolar radiofrequency ablation using perfused- cooled electrodes: a comparative study in the ex vivo bovine liver. Br J Radiol 77(923): 944949.

21. Frieser M, Haensler J, Schaber S, Peters A, Mohelsky E, et al. (2004) Radiofrequency ablation of liver tumors: how to enlarge the necrotic zones? Eur Surg Res 36: 357-361.

22. Moriyasu F (2000) Radiofrequency ablation therapy and blood flow in hepatocellular carcinoma. Cancer 6 (4): S351-355

23. Giorgio A, Tarantino L, de Stefano G, Coppola C, Ferraioli G (2005) Complications after percutaneous saline-enhanced radiofrequency ablation of liver tumors: 3-year experience with 336 patients at a single center. A J R Am J Roentgenol 184(1): 207-211.

24. Boehm T, Malich A, Goldberg SN, Reichenbach JR, Hilger I, et al. (2002) Radio-frequency tumor ablation: internally cooled electrode versus saline-enhanced technique in an aggressive rabbit tumor model. Radiology 222(3): 805-813.

25. Huang JS, Gervais DA, Mueller PR (2001) Radiofrequency ablation: Review of mechanism, indication, Technique and results. Chin J Radiol 26: $119-134$.

\section{Your next submission with Juniper Publishers} will reach you the below assets

- Quality Editorial service

- Swift Peer Review

- Reprints availability

- E-prints Service

- Manuscript Podcast for convenient understanding

- Global attainment for your research

- Manuscript accessibility in different formats

( Pdf, E-pub, Full Text, Audio)

- Unceasing customer service

Track the below URL for one-step submission https://juniperpublishers.com/online-submission.php 